\title{
A Novel Bioflocculant from Raoultella planticola Enhances Removal of Copper Ions from Water
}

\author{
Fancheng Zeng, ${ }^{1}$ Liang Xu $\mathbb{D}^{1,2}$ Caiyun Sun $\mathbb{D}^{1,2}$ Hong Liu, ${ }^{1,2}$ and Libo Chen ${ }^{1}$ \\ ${ }^{1}$ Jilin Institute of Chemical Technology, Jilin, China \\ ${ }^{2}$ School of Chemical Engineering, University of Birmingham, Birmingham, UK \\ Correspondence should be addressed to Liang Xu; xlsdydnl@126.com and Caiyun Sun; suncaiyun1985@126.com
}

Received 7 November 2019; Accepted 6 February 2020; Published 23 July 2020

Guest Editor: Yuan Li

Copyright ( 2020 Fancheng Zeng et al. This is an open access article distributed under the Creative Commons Attribution License, which permits unrestricted use, distribution, and reproduction in any medium, provided the original work is properly cited.

Copper is one of the most toxic heavy metals. In this work, a sampling survey of copper ions in the water of Songhua River flowing through the chemical and living areas of Jilin City was studied. A new bioflocculant from Raoultella planticola was obtained. The investigation of Songhua River flowing through Jilin City shows that the copper concentration is between $0.07 \mathrm{ppb}$ and $0.16 \mathrm{ppb}$. The bioflocculant supporting graphite oxide (GO) as a bioflocculant inducer used in this study has been utilized in treatment of copper ions in water. GO and bioflocculant infrared radiation (IR) spectrum and zeta potential were studied. Flocculational conditions of copper ion $(0.2 \mathrm{ppm})$ were modeled and optimized using RSM (response surface methodology). Our data showed that flocculation efficiency was over $80 \%$. Significant influencing factors and variables were $\mathrm{pH}$, flocculation time, bioflocculant dosage, and GO inducer which had major impact effects on flocculation efficiency. The highest flocculation efficiency which is $86.01 \%$ was achieved at $\mathrm{pH}=5$, at $1.62 \mathrm{~h}$ and $13.11 \mathrm{mg}$ bioflocculant with $13.11 \mathrm{mg} \mathrm{GO}$ as an inducer. However, temperature (A) and GO inducer were significant impact factors on the flocculation efficiency.

\section{Introduction}

Copper is widely used in metallurgy, machine manufacturing, electroplating, chemistry, and other industries. In agriculture and forestry, copper sulfate can prevent diseases and insect pests and inhibit the proliferation of algae in water. Copper chloride, copper sulfate, and copper nitrate are easy to dissolve in water. The total content of copper in a normal human body is about 100-150 mg [1]. However, excessive intake will stimulate the digestive system, causing abdominal pain and vomiting. The oral lethal dose of humans is about $10 \mathrm{~g}$ [2]. The toxicity of copper to lower organisms and crops is relatively high. When the concentration of copper reaches $0.1-0.2 \mathrm{mg} / \mathrm{L}$ [3], fish will die. When it coexists with zinc, the toxicity will increase, and the toxicity to shellfish water will be greater [4]. Generally, the concentration of copper in water for aquaculture is required to be below $0.01 \mathrm{mg} / \mathrm{L}$ [5]. For crops, copper is the most toxic heavy metal, which is fixed in the root cortex after absorbing copper ions, affecting nutrient absorption. When the copper content in irrigation water is high, it accumulates in soil and crops, which can make crops wither [6].

Bioflocculant is a kind of polymer compound. It must be secreted by specific microbial groups under specific growth conditions. The complexity of the molecular components of bioflocculant, such as protein, polysaccharide, and glycoprotein, determines its good electrochemical properties. Therefore, it is endowed with good flocculation characteristics [7, 8]. At present, it is widely explored and studied as a new flocculant. Many publications have reported on bioflocculants to replace traditional industrial flocculants in drinking and wastewater treatment process and fermentation processes because of its high removal efficiency, low dosage, and less secondary pollution in the environment $[9,10]$. Graphene oxide (GO) is a new material which has attracted wide attention in recent years. Because of its excellent electrochemical properties, it has been widely used in electronic technology, biosensors, nanotubes, semiconductors, and other fields. Graphite oxide, as a novel material with a unique structure and excellent properties, has attracted extensive attention 
$[11,12]$. GO is a two-dimensional nanomaterial with a honeycomb-like monolayer structure and has a large number of its surface's active groups, such as epoxy groups, hydroxyl, and carboxyl. GO has an aromatic structure and can adsorb aromatic compounds through the interaction between the active groups and the electron cloud [13].

Therefore, due to graphite oxide's unique structure, there are excellent physical and chemical properties and good biocompatibility. Though graphene oxide has been used as a flocculant in water treatment, the main research is still at the laboratory level, and there are few reports on the actual application of wastewater treatment. The bioflocculant supporting graphite oxide as a bioflocculant inducer used in this study has been studied in the treatment of copper ions in surface water. Accordingly, the objectives of this work are to (1) study a sample survey of copper ions in the water of Songhua River flowing through the chemical and living areas of Jilin City; (2) screen bioflocculantproducing strains for flocculation of copper ions; (3) optimize temperature, $\mathrm{pH}$, bioflocculant dosage, GO inducer, and flocculation time on the flocculation process by response surface methodology (RSM); and (4) analyze the end group properties of bioflocculant and the potential changes in the process of flocculation.

\section{Material and Methods}

2.1. Identification of Bioflocculant-Producing Strains. Approximately 200 isolates $(N-1$ to $N-200)$ were screened from the activated sludge of the Secondary Wastewater Treatment Plant in Jilin, China. The 16s rDNA was amplified by PCR in Shanghai Sangon Biotechnology Co., Ltd. Primers (27F: AGAGTTTGATCCTGGCTCAG and 1492R: GGTT ACCTTGTTACGACTT) were used in 16s rDNA amplification and identification of strains. Sequence similarity was over $97.1 \%$. The comparison of sequencing data showed that the species of the strain was Raoultella planticola by which ncbi access No. is KC456530.1. The Nikon-e100 microscope was used to observe the morphological characteristics of the strain, and the Bergey system bacteriology manual was used to identify the physiological and biochemical characteristics of the strain. Raoultella planticola is a gram-negative, aerobic, rod bacterium.

2.2. Culture Medium for Raoultella planticola Bioflocculant Production. Raoultella planticola was cultivated using beef extract-peptone medium containing $5 \mathrm{~g} / \mathrm{L}$ of peptone, $1.5 \mathrm{~g} / \mathrm{L}$ of beef extract, $1.5 \mathrm{~g} / \mathrm{L}$ of yeast extract, and $5 \mathrm{~g} / \mathrm{L}$ of $\mathrm{NaCl}$. Bioflocculant production culture medium was different from PT-1 which we used in former work [14, 15]. Composition of the bioflocculant medium in this study was as follows: glucose, $20 \mathrm{~g} / \mathrm{L}$; yeast extract, $0.5 \mathrm{~g} / \mathrm{L}$; urea, $0.5 \mathrm{~g} / \mathrm{L}$; $\left(\mathrm{NH}_{4}\right)_{2} \mathrm{SO}_{4}, 0.2 \mathrm{~g} / \mathrm{L} ; \mathrm{KH}_{2} \mathrm{PO}_{4}, 7 \mathrm{~g} / \mathrm{L} ; \mathrm{MgSO}_{4}, 0.2 \mathrm{~g} / \mathrm{L}$; and $\mathrm{NaCl}, 0.1 \mathrm{~g} / \mathrm{L}$. The initial $\mathrm{pH}$ of the medium was adjusted to $7.0 \pm 0.5$. After sterilization, the strain was put into the flask containing the medium, the culture temperature was $30^{\circ} \mathrm{C}$, the vibration frequency was $150 \mathrm{rpm}$, and the best time for bacteria to secrete flocculant was 72 hours.
2.3. Preparation of the Raoultella planticola Bioflocculant (MBF-51). Raoultella planticola was inoculated into a $150 \mathrm{~mL}$ flask containing $50 \mathrm{~mL}$ PT-1 medium. The bioflocculant was termed MBF- 51 and was produced by shaking the flask at $30^{\circ} \mathrm{C}$ at $150 \mathrm{rpm}$ for $72 \mathrm{~h}$. Cell-free supernatants were obtained by centrifugation at $7000 \mathrm{rpm}$ for $30 \mathrm{~min}$. Bioflocculant purification methods were conducted according to previous methods. Briefly, two volumes of cold ethanol (at $4^{\circ} \mathrm{C}$ ) were added to $1 \mathrm{~L}$ culture broth. Following centrifugation at $8000 \mathrm{rpm}$ for $30 \mathrm{~min}$, the precipitate was washed with ethanol, dissolved in $5 \mathrm{~mL}$ of deionized water, and vacuum-dried resulting in approximately $12.50 \pm 0.5 \mathrm{~g}$ of MBF-51 per $1 \mathrm{~L}$ of culture broth.

2.4. Preparation of Nanoscale Graphene Oxide. Graphene oxide was prepared by the modified Hummers method [16]. The preparation steps were as follows: $2.0 \mathrm{~g}$ graphite powder was added into $50 \mathrm{~mL}$ concentrated $\mathrm{H}_{2} \mathrm{SO}_{4}$ solution with $2.0 \mathrm{~g} \mathrm{NaNO}_{3}$ dissolved. After stirring for 15 minutes, $6.0 \mathrm{~g} \mathrm{KMnO}_{4}$ was added slowly (keeping system temperature below $15^{\circ} \mathrm{C}$ ), reaction at $35^{\circ} \mathrm{C}$ for $1 \mathrm{~h}$, heating up to $90^{\circ} \mathrm{C}$ for $15 \mathrm{~min}$, distilled water at $200 \mathrm{~mL}$ was added. Graphite powder was heated with boiling reaction for $15 \mathrm{~min}$. As the graphite dropped to room temperature, it is added with $12 \mathrm{~mL} \mathrm{H}_{2} \mathrm{O}_{2}$ for 8 hours. Then, the mixture is filtered and collected after centrifugation. $\mathrm{SO}_{4}$ ion was removed by washing with distilled water. The powder was vacuum-dried until constant weight. Then, GO powder was obtained. $0.2 \mathrm{~g} \mathrm{GO}$ powder is dispersed in $400 \mathrm{~mL}$ distilled water to make the concentration to $0.5 \mathrm{mg} / \mathrm{mL}$.

2.5. Batch Experiment of Microbial Flocculation of Copper. By adding distilled water, the microbial flocculant MBF-51 was diluted to $60 \mathrm{mg} / \mathrm{L}$ for copper flocculation. The impacts of flocculation conditions (temperature $\left({ }^{\circ} \mathrm{C}\right), \mathrm{pH}$ value, flocculation time (hour), dosage of bioflocculant ( $\mathrm{mg} / \mathrm{L}$ ), and dosage of $\mathrm{GO}$ inducer $(\mathrm{mg} / \mathrm{L})$ ) on flocculation effect were analyzed. The $\mathrm{pH}$ was adjusted from $0.1 \mathrm{M} \mathrm{HCl}$ and $0.1 \mathrm{M}$ $\mathrm{NaOH}$ to about 3.0-1.0. Similarly, the effect of temperature is cultivated at the desired temperature.

After the setting of fixed variable factors, the mixture containing MBF-51 solution, GO inducer, and copper ion $\left(\mathrm{CuCl}_{2}\right)$ was shaken in the track vibrating screen (modehzq-x100, HDL Equipment Co., Ltd., China) and stirred at a constant speed of $250 \mathrm{rpm}$. The initial copper concentration was selected as $0.2 \mathrm{ppm}$ (area No. 4). The optical density of supernatant was measured at the middle height of clarified liquid. The culture medium without flocculant and GO was used as the control. Flocculation efficiency of copper was calculated by

$$
\text { Flocculation Efficiency }(\%)=\frac{A-B}{A} \times 100,
$$

where $A$ is the value of the atomic absorption spectrum determined by the sample and $B$ is the value of the reference sample determined by atomic absorption spectrometry.

2.6. The Establishment of Mathematical Model for the Influence of Different Factors. The Design-Expert software 
TABLE 1: Independent variables and their levels in the experimental design.

\begin{tabular}{lcccccc}
\hline Independent factors & Symbols & -2 & -1 & Code levels & +1 & +2 \\
\hline Temperature $\left({ }^{\circ} \mathrm{C}\right)$ & $\mathrm{A}$ & 5 & 10 & 20 & 30 & 35 \\
$\mathrm{pH}$ & $\mathrm{B}$ & 4 & 5 & 7 & 9 & 10 \\
Flocculation time (hour) & $\mathrm{C}$ & 0 & 0.5 & 1.5 & 2.5 & 3 \\
Bioflocculant dosage (mg/L) & $\mathrm{D}$ & 2.5 & 5 & 10 & 15 & 17.5 \\
GO inducer (mg/L) & $\mathrm{E}$ & 1.5 & 3 & 6 & 9 & 10.5 \\
\hline
\end{tabular}

(8.3 edition) adopts the experimental statistical design and data analysis, and the experimental design is referred to our previous research papers [17]. The narrow temperature, $\mathrm{pH}$ value, flocculation time, the dosage of bioflocculant, and the range of GO inducer were determined before central composite design (CCD) and response surface method (RSM) were used for modeling. The narrower ranges of temperature, $\mathrm{pH}$, flocculation time, bioflocculant dosage, and GO inducer were chosen as $5-35^{\circ} \mathrm{C}, 4-10,0-3$ hours, $2.5-17.5 \mathrm{mg} / \mathrm{L}$, and $1.5-10.5 \mathrm{mg} / \mathrm{L}$, respectively. Five independent factors at different levels $(-2,-1,0,+1$, and +2$)$ were studied. The experimental design is shown in Table 1.

The relationship between the response variable $(y)$ of flocculation efficiency and each factor variable is fitted by the second-order model, and the following quadratic polynomial equation (2) is finally obtained for calculation:

$$
\begin{aligned}
& \text { Flocculation Efficiency }=+80.09+2.79 * A-10.14 * B \\
& +5.65 * C+21.39 * D+4.76 * E \\
& +1.55 * A * \mathrm{~B}-0.84 * A * C \\
& +2.93 * A * D-6.35 * A * E \\
& +0.13 * B * C+1.10 * B * D \\
& +1.95 * B * E+1.06 * C * D \\
& -1.15 * C * E+1.63 * D * E \\
& -1.07 * A^{2}-4.31 * B^{2} \\
& -16.17 * C^{2}-15.88 * D^{2} \\
& +1.64 * E^{2} \text {. }
\end{aligned}
$$

All analyses are in triplicate. The data in the response surface was fitted with the average of three groups of repeated data, and variance analysis was carried out.

2.7. Analytical Methods. Zeta potential measurement was conducted by a zeta potential analyzer (Malvern Nano ZS, Malvern, England). A Fourier-transform infrared spectrometer (Nicolet 6700, ThermoFisher, USA) was used for space atmospheric component detection. A scanning electron microscope (XL30-ESEM, FEI, USA) was used for studies. An atomic absorption spectrometer (180-Series, HITACHI, Japan) was used to determine the total copper concentration in water. The positions and longitude and latitude of the required logging stations are shown in Table 2.

\section{Results and Discussion}

3.1. Investigation on Copper Content in Water in Songhua River Section Flowing through Jilin City. Jilin City is located in the east of the central part of Jilin Province, the northeast hinterland of Changbai Mountains, the junction of Songnen Plain and Changbai Mountains. It is the secondary economic and cultural center of northeast Jilin Province as is shown in Figure 1(a). Its geographical coordinates are between 42 degrees north latitude $31^{\prime}$ to 44 degrees $40^{\prime}$ and 125 degrees $40^{\prime}$ to 127 degrees east longitude $56^{\prime}$. The north and south are about 91 kilometers long and 44 kilometers wide. The total area under the jurisdiction of Jilin City is 27700 square kilometers, of which the urban area is 3774.35 square kilometers; by the end of 2016, the urban area of Jilin City is 498.75 square kilometers, and the built-up area is 189.04 square kilometers. The positions and longitude and latitude of the required logging stations are shown in Table 2 . The investigation in Figure 1(a) shows that the copper concentration in this area is the lowest $0.066 \mathrm{ppb}$ (area No. 10) and the highest is $0.159 \mathrm{ppb}$ (area No. 4). From data in Figure 1(b), it can be seen that the copper content index of the three water samples did not exceed the Class III standard of the Surface Water Quality Standard [18].

3.2. Zeta Potential and Fourier-Transform Infrared Spectrometer Analysis of GO and Bioflocculant. GO and bioflocculant infrared radiation (IR) spectrum was investigated. The IR spectrum of GO exhibited a carboxyl band at 1620, 1582 , and $1384 \mathrm{~cm}^{-1}$ as presented in Figure 2(a). The absorption peaks at $1620 \mathrm{~cm}^{-1}$ and $1582 \mathrm{~cm}^{-1}$ are caused by $\mathrm{C}=\mathrm{O}$ carbonyl expansion and $\mathrm{C}=\mathrm{C}$ expansion in the $\mathrm{GO}$ skeleton, respectively. The absorption peaks at $1384^{-1}$ and $587 \mathrm{~cm}^{-1}$ are related to the deformation vibration of $\mathrm{C}-\mathrm{O}-\mathrm{H}$ and the bending vibration of -O, respectively [19], as shown in Figure 2(a). The adsorption peak at $587 \mathrm{~cm}^{-1}$ indicated the C-O-H stretching vibration [20] as shown in Figures 2(a) and 2(b). Further FTIR characterization of bioflocculant is shown in Figure 1(b). It is found that the peaks of GO and bioflocculant at $2920 \mathrm{~cm}^{-1}$ and $2850 \mathrm{~cm}^{-1}$ correspond to the characteristic absorption peaks of $-\mathrm{OH}$ and $-\mathrm{C}-\mathrm{H}$, respectively [21]. The enhancement of absorption peaks at $3420 \mathrm{~cm}^{-1}$ and $1620 \mathrm{~cm}^{-1}$ is attributed to the $\mathrm{O}-\mathrm{H}$ and $\mathrm{N}-\mathrm{H}$ vibrations in $\mathrm{C}-\mathrm{OH}$ and $\mathrm{N}-\mathrm{OH}$ groups which form hydrogen bonds. Oxygen-containing groups above, especially the strong polar groups such as - $\mathrm{OH}$, are abundant on the surface of the materials, which makes the materials in water-soluble solvents. The dispersion is good, and the polarity is enhanced, and 
TABLE 2: Existing monitoring wells (residential wells, drilling wells, farmland irrigation wells, and centralized water supply wells).

\begin{tabular}{|c|c|c|c|c|}
\hline No. & Name of water source area & Longitude (east longitude) & Latitude (north latitude) & Remarks \\
\hline 1 & Longtan District & $126^{\circ} 29^{\prime} 29^{\prime \prime}$ & $43^{\circ} 55^{\prime} 59^{\prime \prime}$ & Surface water \\
\hline 2 & Songhua River & $126^{\circ} 30^{\prime} 33^{\prime \prime}$ & $43^{\circ} 55^{\prime} 56^{\prime \prime}$ & Surface water \\
\hline 3 & Songhua River & $126^{\circ} 31^{\prime} 52^{\prime \prime}$ & $43^{\circ} 55^{\prime} 36^{\prime \prime}$ & Surface water \\
\hline 4 & Songhua River & $126^{\circ} 32^{\prime} 22^{\prime \prime}$ & $43^{\circ} 54^{\prime} 51^{\prime \prime}$ & Surface water \\
\hline 5 & Songhua River & $126^{\circ} 32^{\prime} 39^{\prime \prime}$ & $43^{\circ} 54^{\prime} 05^{\prime \prime}$ & Surface water \\
\hline 6 & Songhua River & $126^{\circ} 33^{\prime} 45^{\prime \prime}$ & $43^{\circ} 53^{\prime} 36^{\prime \prime}$ & Surface water \\
\hline 7 & Songhua River & $126^{\circ} 34^{\prime} 39^{\prime \prime}$ & $43^{\circ} 53^{\prime} 37^{\prime \prime}$ & Surface water \\
\hline 8 & Songhua River & $126^{\circ} 35^{\prime} 23^{\prime \prime}$ & $43^{\circ} 53^{\prime} 32^{\prime \prime}$ & Surface water \\
\hline 9 & Sewage outfall of Changyi District, Songhua River & $126^{\circ} 36^{\prime} 00^{\prime \prime}$ & $43^{\circ} 53^{\prime} 09^{\prime \prime}$ & Surface water \\
\hline 10 & Sewage outfall of Longtan District, Songhua River & $126^{\circ} 36^{\prime} 12^{\prime \prime}$ & $43^{\circ} 52^{\prime} 42^{\prime \prime}$ & Surface water \\
\hline 11 & Water supply well in Changyi Township & $126^{\circ} 36^{\prime} 07^{\prime \prime}$ & $43^{\circ} 52^{\prime} 17^{\prime \prime}$ & Village-owned wells \\
\hline 12 & Residents in Tiedong Township & $126^{\circ} 35^{\prime} 60^{\prime \prime}$ & $43^{\circ} 51^{\prime} 45^{\prime \prime}$ & Village-owned wells \\
\hline 13 & Songhua River & $126^{\circ} 36^{\prime} 04^{\prime \prime}$ & $43^{\circ} 51^{\prime} 19^{\prime \prime}$ & Surface water \\
\hline 14 & Songhua River & $126^{\circ} 36^{\prime} 08^{\prime \prime}$ & $43^{\circ} 50^{\prime} 27^{\prime \prime}$ & Surface water \\
\hline 15 & Songhua River & $126^{\circ} 35^{\prime} 32^{\prime \prime}$ & $43^{\circ} 49^{\prime} 56^{\prime \prime}$ & Surface water \\
\hline
\end{tabular}

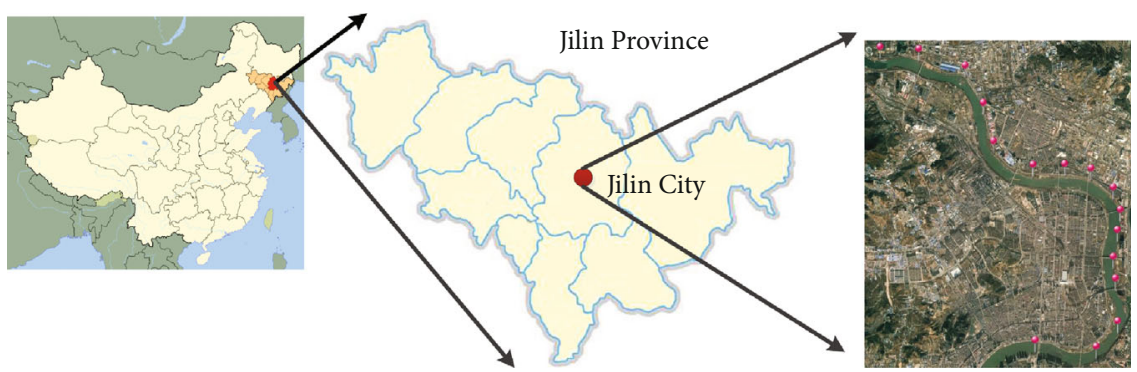

(a)

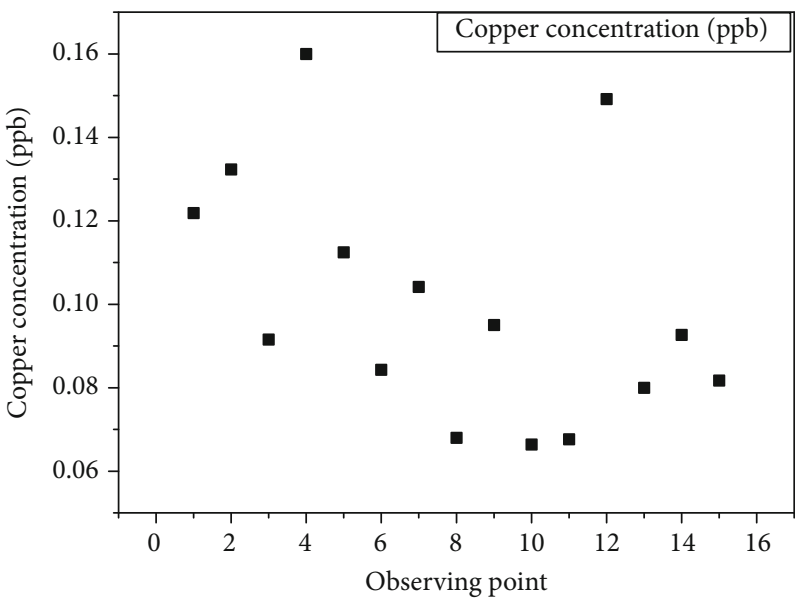

(b)

Figure 1: Copper content in surface water of Songhua River in Jilin City of Jilin Province: (a) sketch map of sampling area; (b) concentration of copper in surface water at 16 sampling sites.

the adsorption of copper by adsorbents is promoted. Zeta potential measurement of bioflocculant with GO inducer solution (Figure 1(c)), indicated that the solution before floc- culation of copper was negatively charged in both alkaline solution and acidic solution; however, zeta potential of the solution after flocculation with copper (Figure 1(d)) was 


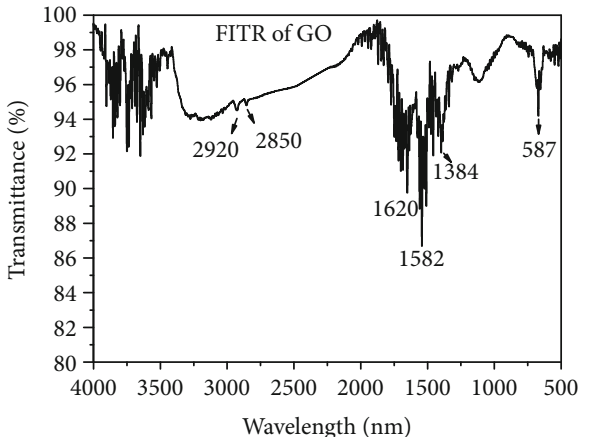

(a)

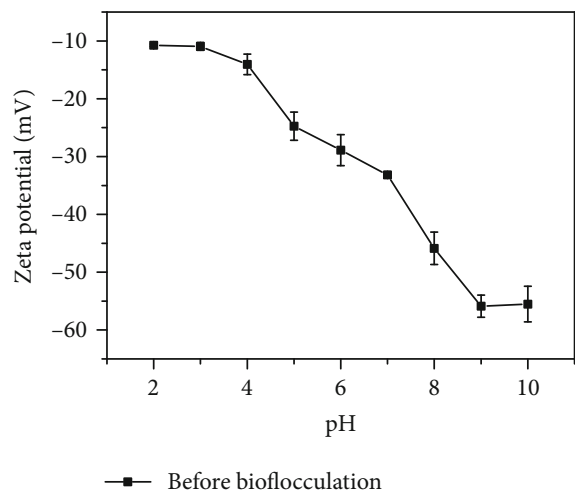

(c)

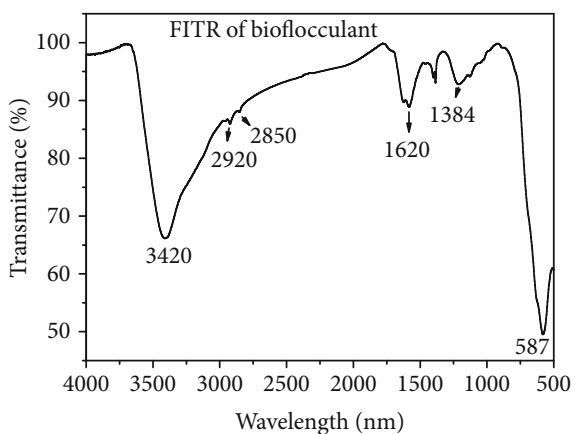

(b)

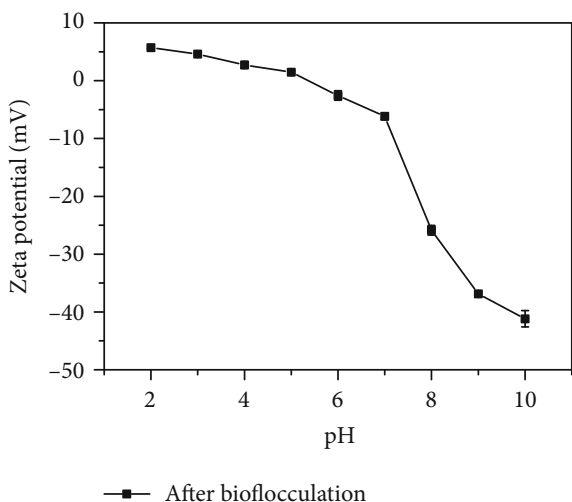

(d)

FIGURE 2: Zeta potential of bioflocculant with GO inducer solution before and after flocculation and Fourier-transform infrared spectrometer analysis of GO and bioflocculant: (a) infrared radiation of GO; (b) infrared radiation of bioflocculant; (c) zeta potential of bioflocculant with GO inducer solution; (d) zeta potential of solution after flocculation.

electrically neutral $(2<\mathrm{pH}<6)$ and was increased by $\mathrm{Cu}(\mathrm{OH})_{2}$ in alkaline $(10<\mathrm{pH}<6)$.

\subsection{RSM Optimization of Copper Flocculation Process}

3.3.1. Analysis of the Effect of Single Factor on Flocculation Efficiency. The experimental tasks and the collected response data are shown in Table 1. As shown in Table 3, the linear terms of $\mathrm{pH}(\mathrm{B})$, flocculation time (C), dosage of bioflocculant (D), and GO inducer (E) have a significant impact on flocculation efficiency ( $F$ value $<0.05$ ), while temperature (A) has no significant impact on flocculation efficiency. Figure 3(a) shows the highest flocculation efficiency achieved at $\mathrm{pH}=5$. With the increase of $\mathrm{pH}$ value from 4 to 5 , the flocculation efficiency increased from $85.65 \%$ to $86.01 \%$, and with the increase of $\mathrm{pH}$ value to 9 , the flocculation efficiency decreased to $65.66 \%$. If the $\mathrm{pH}$ value is changed, the flocculation will be completely different; for example, copper ion will precipitate in alkaline condition. Figure 3(b) shows that the flocculation efficiency reaches the maximum at $1.62 \mathrm{~h}$ and increases from $51.21 \%$ to $80.55 \%$ as the flocculation time increases from 0.05 to $1.62 \mathrm{~h}$ and decreases to $60.16 \%$ as the flocculation time increases to $3 \mathrm{~h}$. Figure 3(c) shows that the flocculation efficiency reaches the maximum at $13.11 \mathrm{mg}$. With the increase of bioflocculant dosage from $2.5 \mathrm{mg}$ to $13.11 \mathrm{mg}$, the flocculation efficiency increased from $12.77 \%$ to $87.26 \%$. With the increase of bioflocculant dosage to
17.5, the flocculation efficiency decreased to $76.60 \%$. Figure 3(d) shows the highest flocculation efficiency achieved at $10.5 \mathrm{mg}$. With the increase of the GO inducer from 1.5 to 10.5 , the flocculation efficiency increased from $76.59 \%$ to $90.88 \%$. Table 3 and Figure 4 show that temperature has no significant effect on flocculation, the flocculation efficiency only increases by $8.39 \%$, and the temperature rises from $5^{\circ} \mathrm{C}$ to $35^{\circ} \mathrm{C}$.

3.3.2. Analysis of the Effect of Two Factors on Flocculation Efficiency. Table 3 shows that temperature (A) and GO inducer (E) are important factors affecting flocculation efficiency. RSM provides a response surface and contour map to study the interaction between parameters and flocculation efficiency in Figure 5 by changing the other two variables in the experimental range and keeping the values of other variables at a medium level. As shown in Figure 3, under the fixed $\mathrm{pH}$ value, flocculation time, and bioflocculant dosage, the flocculation efficiency increases from $48.91 \%$ to $84.46 \%$ as the dosage increases from $5 \mathrm{mg} / \mathrm{L}$ to $15 \mathrm{mg} / \mathrm{L}$; when the dosage of MBF-51 is $10 \mathrm{mg} / \mathrm{L}$, the flocculation efficiency increases from $67.48 \%$ to $75.15 \%$, and the time increases from 0.5 hours to 2.5 hours.

The large surface of GO is rich in oxygen-containing functional groups, such as hydroxyl and carboxyl, which makes it extremely hydrophilic in the water environment (Figure 4(a)), but at the same time, as a lamellar organic 
TABLE 3: Experimental design and results using central composite design.

\begin{tabular}{|c|c|c|c|c|c|c|}
\hline \multirow{2}{*}{ Run } & \multicolumn{5}{|c|}{ Variables } & \multirow{2}{*}{${ }^{\mathrm{a}} \mathrm{FE}(\%)$} \\
\hline & ${ }^{\mathrm{d}} T$ & $\mathrm{pH}$ & ${ }^{\mathrm{b}} \mathrm{FT}$ & ${ }^{c} \mathrm{FD}$ & ${ }^{\mathrm{e}} \mathrm{GI}$ & \\
\hline 1 & 20 & 7 & 1.5 & 10 & 6 & 81.76 \\
\hline 2 & 30 & 5 & 0.5 & 15 & 9 & 76.65 \\
\hline 3 & 10 & 5 & 2.5 & 15 & 9 & 75.65 \\
\hline 4 & 20 & 7 & 1.5 & 10 & 6 & 81.94 \\
\hline 5 & 20 & 7 & 1.5 & 10 & 1.51 & 81.30 \\
\hline 6 & 10 & 5 & 2.5 & 5 & 9 & 66.41 \\
\hline 7 & 10 & 9 & 2.5 & 15 & 9 & 71.87 \\
\hline 8 & 10 & 9 & 0.5 & 5 & 9 & 11.98 \\
\hline 9 & 20 & 7 & 1.5 & 2.52 & 6 & 0.75 \\
\hline 10 & 10 & 5 & 0.5 & 15 & 9 & 69.82 \\
\hline 11 & 30 & 9 & 2.5 & 5 & 9 & 14.10 \\
\hline 12 & 20 & 7 & 0 & 10 & 6 & 0.15 \\
\hline 13 & 20 & 7 & 1.5 & 10 & 6 & 82.86 \\
\hline 14 & 20 & 7 & 1.5 & 17.48 & 6 & 82.77 \\
\hline 15 & 10 & 5 & 2.5 & 15 & 3 & 73.80 \\
\hline 16 & 10 & 9 & 2.5 & 5 & 9 & 12.47 \\
\hline 17 & 20 & 7 & 1.5 & 10 & 6 & 82.17 \\
\hline 18 & 30 & 9 & 0.5 & 15 & 9 & 66.76 \\
\hline 19 & 30 & 9 & 0.5 & 5 & 9 & 11.75 \\
\hline 20 & 30 & 5 & 0.5 & 5 & 9 & 28.80 \\
\hline 21 & 10 & 5 & 0.5 & 5 & 9 & 56.45 \\
\hline 22 & 30 & 5 & 2.5 & 5 & 3 & 46.12 \\
\hline 23 & 10 & 5 & 2.5 & 5 & 3 & 19.39 \\
\hline 24 & 30 & 9 & 2.5 & 5 & 3 & 12.64 \\
\hline 25 & 30 & 9 & 2.5 & 15 & 9 & 73.16 \\
\hline 26 & 30 & 5 & 2.5 & 15 & 3 & 84.07 \\
\hline 27 & 20 & 7 & 3 & 10 & 6 & 82.06 \\
\hline 28 & 30 & 5 & 2.5 & 5 & 9 & 21.78 \\
\hline 29 & 20 & 9.99 & 1.5 & 10 & 6 & 60.78 \\
\hline 30 & 30 & 5 & 2.5 & 15 & 9 & 77.39 \\
\hline 31 & 20 & 7 & 1.5 & 10 & 6 & 82.06 \\
\hline 32 & 10 & 9 & 0.5 & 15 & 9 & 67.29 \\
\hline 33 & 10 & 9 & 2.5 & 5 & 3 & 12.55 \\
\hline 34 & 30 & 5 & 0.5 & 5 & 3 & 42.53 \\
\hline 35 & 20 & 7 & 1.5 & 10 & 6 & 81.76 \\
\hline 36 & 10 & 5 & 0.5 & 15 & 3 & 67.91 \\
\hline 37 & 10 & 5 & 0.5 & 5 & 3 & 7.78 \\
\hline 38 & 30 & 9 & 0.5 & 5 & 3 & 11.93 \\
\hline 39 & 10 & 9 & 0.5 & 5 & 3 & 9.50 \\
\hline 40 & 30 & 9 & 2.5 & 15 & 3 & 62.35 \\
\hline 41 & 20 & 4.01 & 1.5 & 10 & 6 & 74.48 \\
\hline 42 & 10 & 9 & 0.5 & 15 & 3 & 19.10 \\
\hline 43 & 20 & 7 & 1.5 & 10 & 10.49 & 80.57 \\
\hline 44 & 30 & 5 & 0.5 & 15 & 3 & 75.08 \\
\hline 45 & 10 & 9 & 2.5 & 15 & 3 & 32.85 \\
\hline 46 & 20 & 7 & 1.5 & 10 & 6 & 81.61 \\
\hline 47 & 20 & 7 & 1.5 & 10 & 6 & 82.09 \\
\hline
\end{tabular}

TABle 3: Continued.

\begin{tabular}{|c|c|c|c|c|c|c|}
\hline \multirow{2}{*}{ Run } & \multicolumn{5}{|c|}{ Variables } & \multirow{2}{*}{${ }^{\mathrm{a}} \mathrm{FE}(\%)$} \\
\hline & ${ }^{\mathrm{d}} T$ & $\mathrm{pH}$ & ${ }^{\mathrm{b}} \mathrm{FT}$ & ${ }^{c} \mathrm{FD}$ & ${ }^{\mathrm{e}} \mathrm{GI}$ & \\
\hline 48 & 34.95 & 7 & 1.5 & 10 & 6 & 82.06 \\
\hline 49 & 5.05 & 7 & 1.5 & 10 & 6 & 67.67 \\
\hline 50 & 30 & 9 & 0.5 & 15 & 3 & 49.85 \\
\hline
\end{tabular}

matter, its ionic properties are also very good, which is the main reason why we use it as coagulant aids. In the research and experiment, such characteristics play a key role in the removal of copper ions [22]. In the process of flocculation, net catching is the main factor of flocculation mechanism, as shown in Figure 4(b), but at the same time, our experiment shows that due to the function of the GO coagulant aid, electric neutralization and compression double electric layers also play a key role in flocculation. Although we only have data results of zeta potential, it is obvious that such a conclusion is [23]. The induction efficiency of a low dose of $12 \mathrm{mg} / \mathrm{L}$ was over $80 \%$. As a long-chain biopolymer, MBF-51 bridges between GO particles and copper, as shown in Figure 4(b). When MBF-51 is insufficient, a bridging phenomenon will not form effectively. At the same time, even if GO plays the role of compressing the double electric layer to make copper ions adhere to its surface for a short time, because there is not enough bioflocculant, such removal effect cannot be played for a long time, so the dosage of bioflocculant is the guarantee of the removal rate. These oxygen functional groups make GO have good dispersibility in water. As shown in Figure 2, the zeta potential measurement of MBF-51 shows that MBF-51 is mainly negatively charged under alkaline and acidic conditions. It is reported that GO has different electric states at different $\mathrm{pH}$ values. It is a positive charge under acidic conditions ( $\mathrm{pH}$ value lower than 4 ) and a negative charge under neutral and alkaline conditions $(\mathrm{pH}$ value higher than 4). This result just proves that the copper ion, as a cation, can fully connect with GO and bioflocculant to attach and adsorb and finally be removed ([24, 25]).

3.3.3. ANOVA Analysis of Quadratic Model. As shown in Table 4, the experimental data of flocculation efficiency were analyzed by ANOVA. All factors are consistent with the quadratic equation model fitted in the above material method, and our quadratic equation model has significant statistical significance and value, because the results show that our equation $p$ value is far less than 0.05 . The results show that temperature $(A)$ has little effect on flocculation. Its $p$ value is greater than 0.05 (data not shown in Table 3 and Table 4). At the same time, the variance analysis of the response surface quadratic model also proves that temperature is not a key factor in the flocculation process [26]. The $p$ value less than 0.05 indicates that the model term is important, and the insignificant terms $(p$ value $>0.05)$ are removed from the final expression of the model [27]. We assume that the most ideal flocculation efficiency is $100 \%$, and the logit equation is used to fit, and the determined upper limit of the 


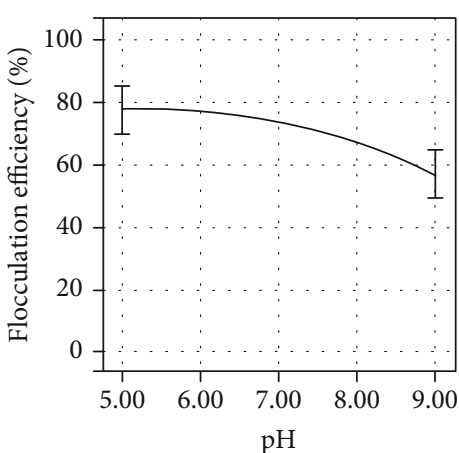

(a)

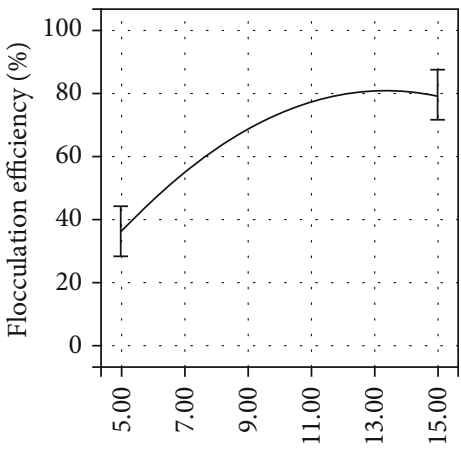

Bioflocculant dosage $(\mathrm{mg} / \mathrm{L})$

(c)

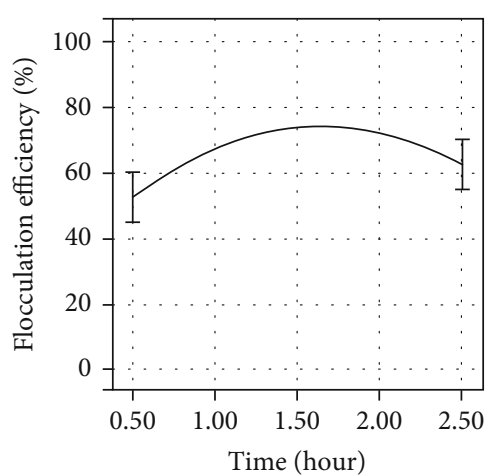

(b)

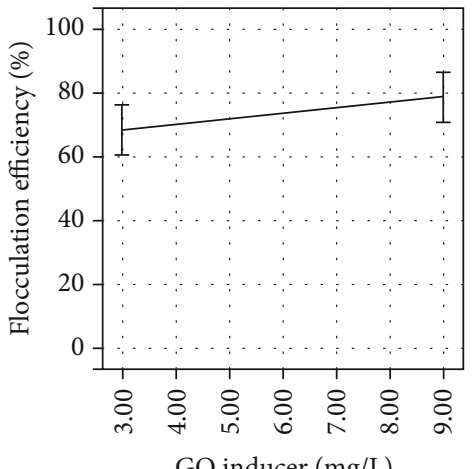

(d)

FIGURE 3: Effect of four linear variable factors on flocculation efficiency, including pH, time, bioflocculant dosage, and GO inducer.

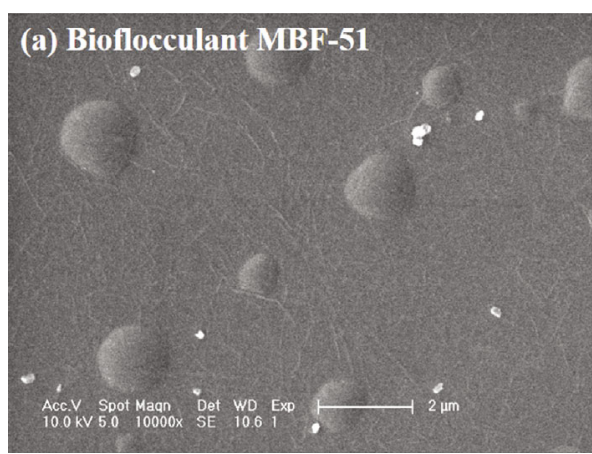

(a)

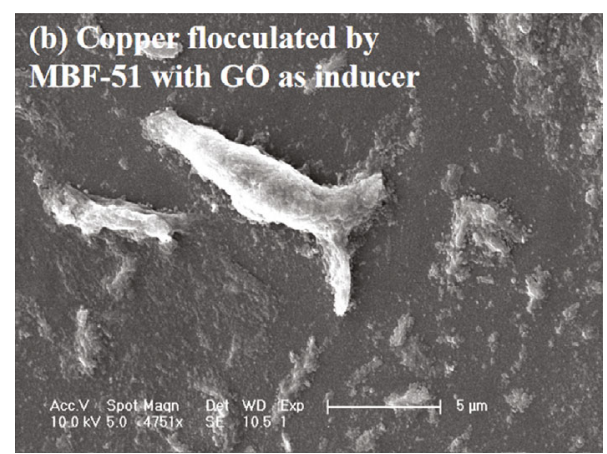

(b)

FIGURE 4: Scanning electron microscopy: (a) bioflocculant MBF-51; (b) copper flocculated by MBF-51 with GO inducer.

dependent variable of flocculation rateyis 100. According to the factor change of the flocculation process and the experiment of five factors without levels, the quadratic equation (2) is finally obtained. As shown in Table 4 , the $p$ value of the equation is less than 0.0001 (far less than 0.05). Using the SNR parameter to evaluate the equation, it is found that the SNR is less than 4, which also has statistical value [28]. The missing of fitting value is not significant compared with the pure error. The correlation coefficient $\left(R^{2}\right)$ obtained in this study is 0.87 , close to $R^{2}$ adj (0.78), indicating that the predicted value of the experiment is in good agreement with the observed value [29].

\section{Conclusions}

The results showed that Raoultella planticola produced flocculant which had never been reported before. The bioflocculant supporting graphite oxide as a bioflocculant inducer used in this study has been studied in the treatment of copper ions in surface water. Raoultella planticola was inoculated in PT-1 medium and resulted in approximately $12.50 \pm 0.5 \mathrm{~g}$ of MBF-51 per $1 \mathrm{~L}$ of culture broth. The investigation of copper ions in the water of Songhua River flowing through the chemical and living areas of Jilin City shows that the copper concentration in this area is between $0.066 \mathrm{ppb}$ and 

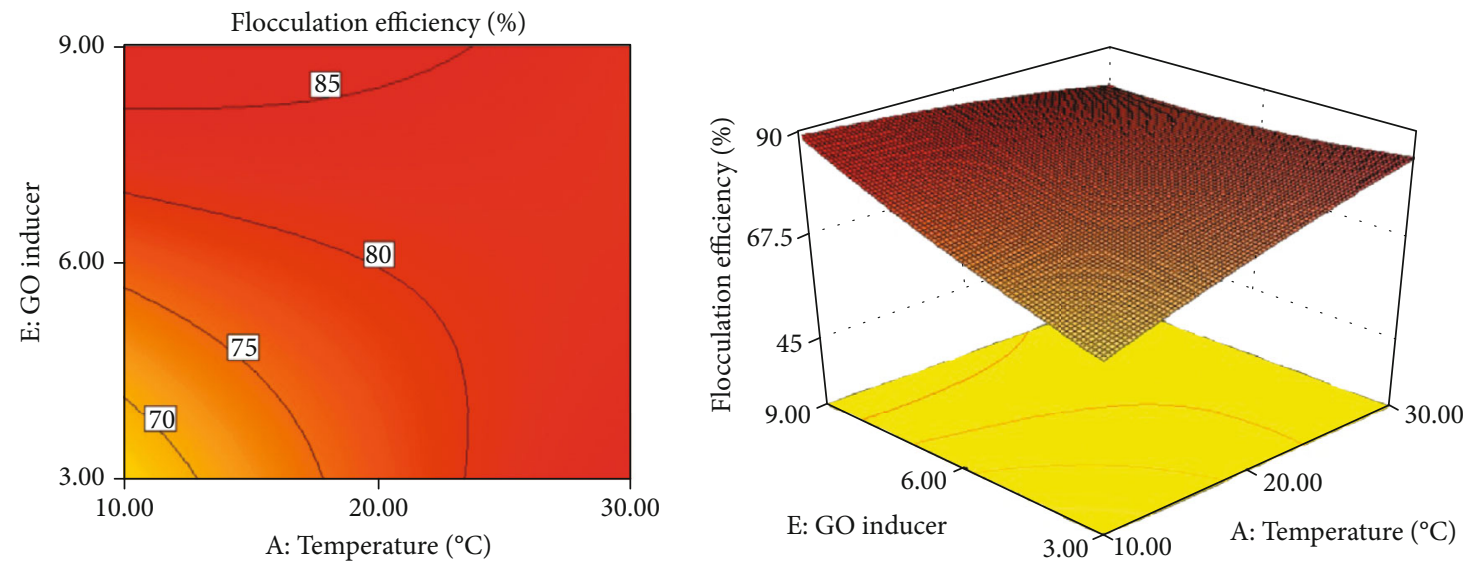

FIGURE 5: Surface responses and contour plots showing two factors affecting flocculation efficiency simultaneously.

TABLE 4: ANOVA analysis for quadratic model.

\begin{tabular}{|c|c|c|c|c|c|}
\hline Source & Sum of squares & $\mathrm{DF}$ & Mean square & $F$ value & $p$ value \\
\hline Model & 36978.58 & 20 & 1848.93 & 9.84 & $<0.0001$ \\
\hline B: $\mathrm{pH}$ & 3752.76 & 1 & 3752.76 & 19.97 & 0.0001 \\
\hline C: time & 1162.27 & 1 & 1162.27 & 6.18 & 0.0189 \\
\hline D: bioflocculant & 16684.25 & 1 & 16684.25 & 88.78 & $<0.0001$ \\
\hline E: GO inducer & 827.94 & 1 & 827.94 & 4.41 & 0.0446 \\
\hline $\mathrm{AE}$ & 1291.13 & 1 & 1291.13 & 6.87 & 0.0138 \\
\hline Residual & 5450.09 & 29 & 187.93 & & \\
\hline Lack of fit & 5449.06 & 22 & 247.68 & 1682.20 & $<0.0001$ \\
\hline Pure error & 1.03 & 7 & 0.15 & & \\
\hline$R$-squared & 0.87 & & & & \\
\hline Adj $R$-squared & 0.78 & & & & \\
\hline Adeq precision & 11.12 & & & & \\
\hline
\end{tabular}

$0.159 \mathrm{ppb}$. Our sampling time is in the dry season, during which the pollutant concentration is the highest. We did not test it at other times. The copper content index of the three water samples did not exceed the Class III standard of the Surface Water Quality Standard. GO and bioflocculant infrared radiation (IR) spectrum were investigated. It is found that the peaks of GO and bioflocculant at $2920 \mathrm{~cm}^{-1}$ and $2850 \mathrm{~cm}^{-1}$ correspond to the characteristic absorption peaks of $-\mathrm{OH}$ and $-\mathrm{C}-\mathrm{H}$, respectively. The enhancement of absorption peaks at $3420 \mathrm{~cm}^{-1}$ and $1620 \mathrm{~cm}^{-1}$ is attributed to the $\mathrm{O}-\mathrm{H}$ and $\mathrm{N}-\mathrm{H}$ vibrations in $\mathrm{C}-\mathrm{OH}$ and $\mathrm{N}-\mathrm{OH}$ groups which form hydrogen bonds. Oxygen-containing groups above, especially the strong polar groups such as $-\mathrm{OH}$, are abundant on the surface of the materials, which promoted the adsorption of copper. Zeta potential measurement of bioflocculant with GO inducer solution indicated that the solution before flocculation of copper was negatively charged in both alkaline solution and acidic solution. Flocculation conditions of copper ion $(0.2 \mathrm{ppm})$ were optimized using response surface methodology. The results showed that the highest flocculation efficiency over $80 \%$ occurred under optimistic conditions. We determined the influencing factors and the corresponding value range through the preexperiment.
At the same time, in the preexperiment, we also found that the bioflocculant aid GO also has a certain adsorption effect on copper ions. We use the adsorption here because we found the phenomenon of saturation and desorption in the experiment. The linear terms for $\mathrm{pH}$ (B), flocculation time (C), bioflocculant dosage (D), and GO inducer (E) had significant effects on flocculation efficiency $(F$ value $<0.05)$, but temperature (A) had no significant effects on the flocculation efficiency. The highest flocculation efficiency which is $86.01 \%$ was achieved at $\mathrm{pH}=5$, at $1.62 \mathrm{~h}$ and $13.11 \mathrm{mg}$ bioflocculant with $13.11 \mathrm{mg}$ GO as an inducer. The influence of temperature on flocculation was not significant, and the flocculation efficiency just increased by $8.39 \%$, with temperature rising from 5 to $35^{\circ} \mathrm{C}$; however, the temperature (A) and $\mathrm{GO}$ inducer (E) were significant impact factors on the flocculation efficiency. As for the mechanism of flocculation, our SEM results do not fully explain the mechanism. However, we speculate that the flocculation removal of copper ions is mainly due to the adsorption and compression of double electric layers. This research has some special significance and value compared with the previous research in our laboratory, although it seems that the research methods and article structure are similar [14]. First of all, this article found a new 
strain. According to our research results, the flocculant production of this strain is very competitive, and the flocculant secretion ability of this strain is much higher than that of the strain mentioned in the previous article [14, 17]. Second, another difference is that graphene oxide is no longer regarded as a pollutant in this work but developed by us as a coagulant aid. This is also because of the use of graphene oxide itself, which has produced new and different flocculation mechanisms and effects. I think this is the greatest value of this article. At the same time, the nanosized GO plays a key role in this process, which may include both adsorption and ion balance change. But we still lack further research and data.

\section{Data Availability}

The data used to support the findings of this study are included within the article.

\section{Conflicts of Interest}

The authors declare that they have no conflicts of interest.

\section{Acknowledgments}

This work was supported by the National Natural Science Foundation of China (Nos. 51708248, 51708094, and 51908241) and funded by the China Scholarship Council (No.201808220182), Doctoral Fund of Jilin Institute of Chemical Technology (No. 2018001), and Program of Science and Technology of Jilin Institute of Chemical Technology (No. 2018044). I also want to thank the support of the China Scholarship Council.

\section{References}

[1] T. Lech and J. Sadlik, "Copper concentration in body tissues and fluids in normal subjects of southern Poland," Biological Trace Element Research, vol. 118, no. 1, pp. 10-15, 2007.

[2] G. Arakeri, S. Patil, D. Ramesh, S. Hunasgi, and P. Brennan, "Evaluation of the possible role of copper ions in drinking water in the pathogenesis of oral submucous fibrosis: a pilot study," British Journal of Oral and Maxillofacial Surgery, vol. 52, no. 1, pp. 24-28, 2014.

[3] Y. Li, Z. Gu, H. Liu, H. Shen, and J. Yang, "Biochemical response of the mussel Mytilus coruscus(Mytiloida:Mytilidae) exposed to in vivo sub-lethal copper concentrations," Chinese Journal of Oceanology and Limnology, vol. 30, no. 5, pp. 738745, 2012.

[4] A. A. Filippov and I. L. Golovanova, "Separate and joint effects of copper and zinc on the intestine carbohydrase activity in vitro in freshwater teleosts," Inland Water Biology, vol. 3, no. 1, pp. 96-101, 2010.

[5] L. Song, M. G. Vijver, W. J. G. M. Peijnenburg, T. S. Galloway, and C. R. Tyler, "A comparative analysis on the in vivo toxicity of copper nanoparticles in three species of freshwater fish," Chemosphere, vol. 139, pp. 181-189, 2015.

[6] A. Bhatia, S. D. Singh, and A. Kumar, "Heavy metal contamination of soil, irrigation water and vegetables in peri-urban agricultural areas and markets of Delhi," Water Environment Research, vol. 87, no. 11, pp. 2027-2034, 2015.
[7] Q. Liu, C. Zhao, D. Zhao, and Y. Zhang, "Screening of Bioflocculant-Producing Strains and Study on the Production and Oily Wastewater Flocculation Characteristics," in 2012 2nd International Conference on Remote Sensing, Environment and Transportation Engineering, Nanjing, China, 2012.

[8] P. Sun, C. Hui, N. Bai et al., "Revealing the characteristics of a novel bioflocculant and its flocculation performance in _Microcystis aeruginosa_removal," Scientific Reports, vol. 5, p. 17465, 2015.

[9] L. Peng, C. Yang, G. Zeng et al., "Characterization and application of bioflocculant prepared by Rhodococcus erythropolis using sludge and livestock wastewater as cheap culture media," Applied Microbiology and Biotechnology, vol. 98, no. 15, pp. 6847-6858, 2014.

[10] S. Zaki, M. Elkady, S. Farag, and D. Abd-El-Haleem, "Characterization and flocculation properties of a carbohydrate bioflocculant from a newly isolated Bacillus velezensis 40B," Journal of Environmental Biology, vol. 34, no. 1, pp. 51-58, 2012.

[11] X. Hu, Y. Yu, J. Zhou, and L. Song, "Effect of graphite precursor on oxidation degree, hydrophilicity and microstructure of graphene oxide," Nano, vol. 9, no. 3, p. 1450037, 2014.

[12] X. Ji, Y. Xu, W. Zhang, L. Cui, and J. Liu, "Review of functionalization, structure and properties of graphene/polymer composite fibers," Composites Part A: Applied Science and Manufacturing, vol. 87, pp. 29-45, 2016.

[13] Q.-J. Wang, H.-J. Sun, T.-J. Peng, and M.-Z. Feng, "Structure development during the cation exchange processes of graphite oxide," Acta Physico-Chimica Sinica, vol. 33, no. 2, pp. 413418, 2017

[14] L. Xu, R. S. Ma, C. Y. Sun, and D. Z. Sun, "Enterococcus faecalis bioflocculant enhances recovery of graphene oxide from water," Polish Journal of Environmental Studies, vol. 27, no. 6, pp. 2811-2820, 2018.

[15] Z. H. Yang, Y. Tao, G. M. Zeng, Y. Xiao, and E. J. Deng, "Culture medium and grading culture technics for bioflocculant production by Paenibacillus polymyxa GA1," Environmental Science, vol. 27, pp. 1444-1449, 2006.

[16] H. Yu, B. Zhang, C. Bulin, R. Li, and R. Xing, "High-efficient synthesis of graphene oxide based on improved hummers method," Scientific Reports, vol. 6, no. 1, 2016.

[17] L. Xu, M. Huo, W. Yang, D. Zhou, and H. Huo, "Klebsiella pneumoniaemetabolites enhanceMicrocystis aeruginosabiomass flocculation," Chemistry and Ecology, vol. 32, no. 9, pp. 858-871, 2016

[18] Y. Wang, K. Tang, J. Weng, and R. Wang, "Research on water quality standards of drinking water sources," China Standardization, vol. 3, pp. 70-74, 2014.

[19] Y. L. Pei, Z. S. Wu, X. Y. Shi, X. N. Pan, and Y. J. Qiao, "Nir assignment of magnolol by $2 \mathrm{~d}$-cos technology and model application huoxiangzhengqi oral liduid," Guang pu xue yu guang pu fen $x i=$ Guang $p u$, vol. 35, no. 8, pp. 2119-2123, 2015.

[20] G. A. Pitsevich, A. E. Malevich, E. N. Kozlovskaya et al., "Theoretical study of the C-H/O-H stretching vibrations in malonaldehyde," Spectrochimica Acta Part A: Molecular and Biomolecular Spectroscopy, vol. 145, pp. 384-393, 2015.

[21] Y. Li, et al.H. A. Ma, X. Jia et al., "Electrical properties of diamond single crystals co-doped with hydrogen and boron," CrystEngComm, vol. 16, no. 32, p. 7547, 2014. 
[22] J. Vlček, L. Lapčík, M. Havrdová et al., "Flow induced HeLa cell detachment kinetics show that oxygen-containing functional groups in graphene oxide are potent cell adhesion enhancers," Nanoscale, vol. 11, no. 7, pp. 3222-3228, 2019.

[23] Y. Li, Y. Xu, T. Zheng, and H. Wang, "Flocculation mechanism of the actinomycete Streptomyces sp. hsn06 on Chlorella vulgaris," Bioresource Technology, vol. 239, pp. 137-143, 2017.

[24] O. Bajjou, A. Bakour, M. Khenfouch et al., "Charge carrier dynamics and ph effect on optical properties of anionic and cationic porphyrin-graphene oxide composites," Journal of Electronic Materials, vol. 47, no. 5, pp. 2897-2904, 2018.

[25] Y. Q. He, H. B. Chen, H. Sun, X. D. Wang, and J. P. Gao, “A pH and electric responsive graphene oxide based composite hydrogel," Advanced Materials Research, vol. 430-432, pp. 327-330, 2012.

[26] H. Ding, P.-M. Feng, W. Chen, and H. Lin, "Identification of bacteriophage virion proteins by the ANOVA feature selection and analysis," Molecular BioSystems, vol. 10, no. 8, pp. 22292235, 2014.

[27] J. Dick and M. Gnewuch, "Optimal randomized changing dimension algorithms for infinite-dimensional integration on function spaces with anova-type decomposition," Journal of Approximation Theory, vol. 184, pp. 111-145, 2014.

[28] A. O. J. Cramer, D. van Ravenzwaaij, D. Matzke et al., "Hidden multiplicity in exploratory multiway anova: prevalence and remedies," Psychonomic Bulletin \& Review, vol. 23, no. 2, pp. 640-647, 2016.

[29] A. Cuevas, M. Febrero, and R. Fraiman, "An anova test for functional data," Computational Statistics \& Data Analysis, vol. 47, no. 1, pp. 111-122, 2004. 